\title{
Reply to letter to the editor: Comparison of retinal detachment surgery outcome among patients undergoing pars plana vitrectomy with and without relaxing retinotomy
}

\author{
Adiel Barak ${ }^{1}$ \\ Received: 13 July 2015 / Accepted: 18 July 2015 / Published online: 6 August 2015 \\ (C) Springer-Verlag Berlin Heidelberg 2015
}

\section{Dear Editor,}

We thank Dr. Murat Kucukevcilioglu and Dr. Ali Hakan Durukan for their kind words regarding our manuscript, and for allowing us to clarify the points that need clarification:

1. The definition of "complicated retinal detachment": As we said in the discussion, we do not have a systematic method of recording the degree of PVR. Because of this, we decided that for comparison reasons, we would consider a "complicated retinal detachment" as all cases in which surgery ended with silicone oil (as opposed to gas). In noncomplicated cases, our preferred tapenade for retinal detachment cases is gas injection (not expensile SF6 $20 \%$ or C3F8 $16 \%$ ). Thus, the surgeon's decision to use silicone oil at the end of surgery is an indication of its complexity.

2. The sclerotomy size used during the surgery: During the study period of 2006 to 2009 , we used only $20 \mathrm{G}$ vitrectomy systems with trocars: until 2008, we used the Grieshaber ${ }^{\circledR} 20$-g trocar system, which was sutured using 7-0 Vycril sutures; and during 2008-2009, the majority of cases were done using the Dorc ${ }^{\circledR}$ sutureless valved 20-g transconjunctival trocar system, which were left unsutured after the silicone oil injection. We have previously published our data regarding the use of the 20-G sutureless system [1] including the rate of hypotony. In $3 \%$ of 102 eyes (including those which were tamponade with BSS, air, gas, and silicone oil), hypotony was observed on the

Adiel Barak

adielbarak@gmail.com

1 Department of Ophthalmology, The Tel Aviv Medical Center, Tel Aviv University, 6 Waitzman Street, Tel Aviv 45267, Israel day after the operation, but did not persist for longer than a week. We did not record any case of hypotony among eyes which were tamponade with silicone oil.

3. Macular hole surgery following retinotomy: We do not think that the macular hole developed because of the retinotomy, but rather as a complication of the vitrectomy procedure, and we refer the reader to our previous manuscript on this subject [2]. We can speculate that the more complicated surgery has higher chances of causing complications as a macular hole formation, but we have no proof of such speculation.

4. Four patients with macular holes were not operated after the macular hole discovery. In two of these patients, the hole was large and without any cystic changes, thus our clinical impression was that the chances of hole closure were slim, and we recommended the patient not to undergo another surgery. The third patient developed a macular hole in the extremely high myopic eye, and again we thought the chances of hole closure were minimal. The fourth patient did ot additional surgeries due to complicated systemic health problems.

Again, we want to thank Dr. Murat Kucukevcilioglu and Dr. Ali Hakan Durukan and the Graefe's Archive for Clinical and Experimental Ophthalmology for allowing us to clarify our manuscript.

\section{References}

1. Spierer O, Siminovsky Z, Loewenstein A, Barak A (2011) Outcomes of 20-gauge transconjunctival sutureless vitrectomy. Retina 31(9): 1765-1771

2. Fabian ID, Moisseiev E, Moisseiev J, Moroz I, Barak A, Alhalel A (2012) Macular hole after vitrectomy for primary rhegmatogenous retinal detachment. Retina 32(3):511-519 